\title{
A HISTÓRIA DA EDUCAÇÃO E O ENSINO ANALISADOS EM DUAS OBRAS CLẢSSICAS: CÁRCEL DE AMOR E LA VIDA DE LAZARILLO DE TORMES
}

\author{
DOI: http://dx.doi.org/10.1590/2236-3459/64229
}

\author{
Conceição Solange Bution Perin \\ Universidade Estadual do Paraná (Unespar), Paranavaí/Paraná, Brasil \\ Silvana Malavasi \\ Universidade Estadual do Paraná (Unespar), Apucarana/Paraná, Brasil
}

$\cos 8$

\begin{abstract}
Resumo
O estudo tem como objetivo analisar duas obras clássicas, no ensino da literatura espanhola medieval: Cárcel de Amor, escrita no século XV por Diego de San Pedro, e La vida de Lazarillo de Tormes, romance anônimo escrito no século XVI, no ensino. Partimos do pressuposto que, as obras clássicas auxiliam-nos a entender melhor o passado e, consequentemente, podem ser consideradas como instrumentos para a compreensão e desenvolvimento do ensino. O objetivo central é evidenciar, por meio das obras, os acontecimentos cotidianos de cada período e analisar, como exemplo em Cárcel de Amor, a luta pela manutenção do amor e sentimentos demonstrados, principalmente, pelos nobres. Tais sentimentos tornaram-se modelo de aprendizado para a organização da sociedade. Para atender tal propósito por meio de um estudo bibliográfico, embasado na análise histórica promovida e fundamentada por autores da História Social, como Marc Bloch, apresentamos os aspectos de ensino e a aprendizagem presentes nas duas obras. Em seguida, abordamos as obras clássicas e seu conhecimento histórico para o ensino.

Palavras-chave: história da educação, ensino, obras clássicas, literatura espanhola.
\end{abstract}

\section{THE HISTORY OF EDUCATION AND TEACHING DISCUSSED IN TWO CLASSICAL WORKS: CÁRCEL DE AMOR AND LA VIDA DE LAZARILLO DE TORMES}

\begin{abstract}
This study aims to analyze the use of two classic works in the teaching of medieval Spanish literature: Cárcel de Amor, written in the fifteenth century by Diego de San Pedro, and La vida de Lazarillo de Tormes, anonymous novel written in the sixteenth century, in teaching. We assume that the study of classic works helps us to better understand the past. The primary goal is to highlight, through the works, everyday events of each period and to analyze, as an example in Cárcel de Amor, the struggle for the maintenance of love and other feelings demonstrated, mainly, by the nobleness. Such feelings became a learning model for the organization of society. To meet this purpose through a bibliographic study, based on promoted historical analysis and supported by authors of Social History, as Marc Bloch, we present aspects of teaching and learning in the two works. Then we approach the classical works and his historical knowledge for teaching.

Keywords: history of education, teaching, classical works, spanish literature.
\end{abstract}




\section{LA HISTORIA DE LA EDUCACIÓN Y LA ENSEÑANZA ANALIZADAS EN DOS OBRAS CLÁSICAS: CÁRCEL DE AMOR Y LA VIDA DE LAZARILLO TORMES}

\section{Resumen}

El estudio tiene como objetivo analizar dos obras clásicas de la literatura española medieval: Cárcel de Amor, escrita en el siglo XV por Diego de San Pedro, y La vida de Lazarillo de Tormes, novela anónima escrita en el siglo XVI, en la enseñanza. El objetivo central es evidenciar, por medio de las obras, los acontecimientos cotidianos de cada período y analizar, como ejemplo en Cárcel de Amor, la lucha por la manutención del amor y de los demasiados sentimientos expuestos, principalmente, por los nobles y que se volvieran como modelo del aprendizaje para la organización de la sociedad. Creemos que el estudio de las obras clásicas nos ayuda a comprender mejor el pasado Para atender este propósito a través de un estudio bibliográfico, basado en el análisis histórico promovido y apoyado por los autores de la historia social, como Marc Bloch, presentan aspectos de la enseñanza y el aprendizaje presentes en las dos obras. En seguida se discuten las obras clásicas y su conocimiento histórico para la enseñanza.

Palabras clave: historia de la educación, enseñanza, obras clásicas, literatura española.

\section{L'HISTOIRE DE L'ÉDUCATION ET L'ENSEIGNEMENT À PARTIR DE DEUX OEUVRES CLASSIQUES: CÁRCEL DE AMOR ET LA VIDA DE LAZARILLO DE TORMES}

Cette étude vise à analyser l'utilisation de deux œuvres classiques de la littérature espagnole médiévale dans l'enseignement: Cárcel de Amor, écrit au XVe siècle par Diego de San Pedro, et La vida de Lazarillo de Tormes, roman anonyme écrit au XVIe siècle. Nous partons de la prémisse que l'étude des œuvres classiques nous aide à mieux comprendre le passé. L'objectif principal est de démontrer, au moyen d'œuvres, les événements quotidiens de chaque période et analyser, par exemple dans Cárcel de l'amour, la lutte pour maintenir l'amour et les sentiments démontrés principalement par les nobles. De tels sentiments sont devenus modèle d'apprentissage pour l'organisation de la société. Pour atteindre cet objectif en utilisant une étude bibliographique basée sur l'analyse historique fondée et répandue par des auteurs de l'histoire sociale, comme Marc Bloch, nous présentons les aspects de l'enseignement et de l'apprentissage dans les deux œuvres. Ensuite, nous abordons les œuvres classiques et ses connaissances historiques pour l'enseignement. Mots-clés: historie de l'éducation, éducation, œuvres classiques, littérature espagnole. 


\section{Considerações iniciais}

A atenção dos atores envolvidos no processo educacional da atualidade precisa estar voltada para as questões históricas, pois estas favorecem a reflexão acerca das questões que os afetam. Ao mesmo tempo, para compreender contextos de outros momentos, não basta tomar como base estudos realizados por autores contemporâneos. Mesmo tendo esses momentos como seus objetos de estudo, esses autores, normalmente, estão imersos nos acontecimentos atuais da sociedade e buscam responder a algumas questões microssociais momentâneas. De nossa perspectiva, para compreender a essência dos eventos atuais, para entender o presente e poder compreender alguns dos embates da sociedade contemporânea, é importante recorrermos à historicidade ${ }^{1}$.

No que tange à leitura e à utilização de obras clássicas em contextos acadêmicos, o que predomina é o descompromisso com o contexto histórico. Conforme Leonel (1998), no contexto das constantes transformações tecnológicas, o estudo de obras clássicas no meio acadêmico é muitas vezes considerado despropósito, um disparate, de forma que poucos professores as utilizam em suas práticas de ensino. Ponderamos que, na realidade, a falta de comprometimento dos professores com a utilização desses textos em suas aulas resulta em lacunas na formação dos futuros professores, que deixam de se beneficiar do conhecimento neles contido, especialmente quanto aos acontecimentos históricos. A falta de contato direto dos alunos com essa literatura apresenta-se na organização da sociedade e, especificamente, no sistema educacional.

Considerando a importância do estudo de obras clássicas para o ensino, analisamos duas obras da literatura espanhola medieval, Cárcel de Amor, século XV, de Diego de San Pedro e La vida de Lazarillo de Tormes, século XVI, autor anônimo. Para compreender o sentido de tais obras no ensino, esse estudo encontra-se dividido em dois momentos. Primeiramente descrevemos os aspectos de ensino e aprendizagem nas obras clássicas Cárcel de Amor e La vida de Lazarillo de Tormes. Em seguida, apontamos as obras clássicas e seu conhecimento histórico para o ensino.

\section{Aspectos de ensino e da aprendizagem em Cárcel de amor e Lazarrillo de Tormes}

O estudo das duas obras da literatura clássica espanhola é importante para o ensino, principalmente nos cursos de licenciatura, justamente porque, por meio delas, os futuros professores podem lançar um olhar diferenciado para a formação humana e compreender que esta é marcada pelas peculiaridades de cada período histórico. De nossa perspectiva, sua utilização no processo de formação docente favorece o entendimento das relações desenvolvidas entre os homens ao longo dos tempos.

Em Cárcel de Amor, temos contato com temas relacionados com o fortalecimento do amor; a dor da rejeição; a traição; a lealdade e a fé. Nesse cenário, os hábitos da

\footnotetext{
${ }^{1}$ Consideramos que entender as questões históricas cotidianas é uma busca sobre as relações humanas e a importância da historicidade para a compreensão do presente. Segundo Le Goff (2014) no prefácio do livro de Marc Bloch (1949) Apologia da História (2001, p. 24) "A história é busca, portanto escolha. Seu objeto não é o passado: "A própria noção segundo a qual o passado enquanto tal possa ser objeto de ciência é absurda." Seu objeto é "o homem", ou melhor, "os homens", e mais precisamente "homens no tempo"'.
} 
nobreza, bem como a educação e o ensino destinados às pessoas que viviam no século $X V$ são mostrados por seus diferentes personagens. De nossa perspectiva, o tema central de Cárcel de Amor é o amor, ou seja, a emoção prevalece nessa obra. O amor fazia parte da vivência dos homens e expressava o conceito ou ideia superior que determinava 0 desenvolvimento do próprio ser humano de então. (SAN PEDRO, 2010). É oportuno frisar que esse conceito não dependia unicamente das atitudes dos protagonistas, era uma expressão da vida, ligava-se direta ou indiretamente com os acontecimentos da vida das pessoas. A esse tema estão relacionados os argumentos, as ações e os conteúdos que compõem o romance de Diego de San Pedro. Casanova (2008) relata que em nenhum outro momento da cultura espanhola o amor pelas mulheres foi tão exaltado como nos séculos XII ao XV.

A nosso ver, a forma como o nobre cavaleiro, Leriano, se apaixonou por Laureola e foi recusado por ela expõe a força do amor, revela que ele era um código social do século $X V$. O romance foi estruturado sobre essa base, representando uma ruptura com os modelos sociais estabelecidos nessa época. Aparecem o sofrimento e a dor pelo sentimento não correspondido, dor que até então não existia, a rejeição, o fracasso do ser humano, ou seja, o personagem é movido por um ideal impossível, o amor por uma mulher idealizada. Esse amor idealizado transforma-se em lealdade para com a amada, de forma que Leriano, mesmo rejeitado, mantém-se leal ao seu objeto. Enfatizamos que a fé e a razão são um contrapeso social para a novela de Diego de San Pedro. A dualidade entre a fé e a razão é o fundo sobre o qual a história acontece, sendo que a dama é caracterizada como um objeto de culto religioso e de veneração. A razão foi destruída, invadida pelo ideal inalcançável. Dessa forma, sem Ihe dar condições de voltar ao mundo da realidade, a fé de Leriano o levou à morte "Con dolor será ni vivir, ni comer, ni pensar y ni dormir, hasta que su fuerza y mi deseo me lleven a tu sepultura". (SAN PEDRO, 2010, p. 290).

Segundo nossa análise, ainda no século XV, a nobreza tentava manter seus costumes, suas preocupações, valorizando a contemplação, o conhecimento pela via da fé. Por meio de Cárcel de Amor, cujo cenário é da vida na corte, com as festas promovidas pela nobreza, podemos afirmar que estas revelam uma série de comportamentos, dentre os quais a inveja e a traição prevalecem como pano de fundo do romance. Apesar de o autor valorizar a nobreza, procurando mostrar os bons hábitos que circundam o meio social, apresentou também outros sentimentos, a exemplo da inveja e da traição. Embora elas sempre tenham existido entre os homens, ou seja, aparecem tanto no passado quanto no presente, sendo aspectos da vida cotidiana, em alguns momentos elas se sobressaem, em razão das próprias relações sociais. No caso, esses outros sentimentos estão em evidência porque a sociedade passou a se fundar no comércio, no convívio mais próximo.

Esse encaminhamento se destacava porque, no século $\mathrm{XV}$, as mudanças sociais estavam mais explícitas. O comércio e as cidades eram os centros de investimentos das duas sociedades que conviviam e, ao mesmo tempo, lutavam por questões diferentes. De um lado, uma parte da sociedade procurava manter o domínio da nobreza, a representação do cavaleiro, a corte enaltecida pelos bons hábitos educacionais, pela aparência e pela liderança na sociedade. Do outro lado, a realidade do homem moderno revelava que as prioridades do dia a dia eram uma contradição em relação ao que estava posto na sociedade como verdade. Uma parte dos homens queria adquirir novos ensinamentos, realizar novas experiências e descobertas, ou seja, queria explorar o mundo do comércio. 
$\mathrm{Na}$ interpretação de Casanova (2008), Diego de San Pedro é didático, pois busca ensinar uma moral ou simplesmente propor um alerta, usando como exemplo a história dos apaixonados "Pero como los primeros movimientos no se pueden en los hombres excusar, en lugar de desviarlos con la razón confírmelos con la voluntad, y así de Amor me vencí, que me trajo a esta su casa, la cual se llama Cárcel de Amor". (SAN PEDRO, 2010, p. 3738). O fato é que, no século $X V$, o autor retrata uma sociedade cortês, na qual os conteúdos dos novos gêneros literários representavam as novas formas de amor. Com isso, indica as formas pelas quais o novo homem poderia tentar transformar suas necessidades em objetivos concretos. Em síntese, é importante utilizar essa obra clássica da literatura espanhola medieval nos cursos de formação de professores, tanto pelos professores formadores quanto pelos alunos, pois ela envolve o conhecimento histórico. Revela também as preocupações dos homens em um momento de alteração social, seus sentimentos, as relações pessoais que se expressavam na leitura e a escrita, o conhecimento de regiões. Torna possível criar uma base sólida de conhecimentos teóricos e práticos em sua totalidade.

Já, em La vida de Lazarillo de Tormes, priorizando o uso da razão, os tratados compostos pelos relatos de Lázaro a respeito do que vivenciou com seus diversos amos, ou seja, com os homens de seu tempo, transmitem-nos uma mensagem de vida, deixamnos lições de aprendizagem para a vida. (ANÔNIMO, 1975). Essa obra relata o lado pobre da Espanha, ou seja, a decadência de um país, ao passo que Cárcel de Amor retrata a nobreza. Chegamos a afirmar que o primeiro amo de Lázaro foi o seu primeiro mestre. Esse personagem era um mendigo cego que lhe ensinou artimanhas para viver em um mundo miserável, onde a fome era um fato lamentável. Esse cenário representa a Espanha do século XVI.

Esse mestre cego, atuando com base nos conhecimentos que ele adquirira por vivência, ensina o pobre Lázaro a compreender que a vida era muito dura, que precisava estar sempre atento "[...] dije que sí, como era verdad, que aunque maltratado, mil cosas buenas me mostró el pecador ciego, y una de ellas fue ésta". (ANÔNIMO, 1975, p. 113). O cego era extremamente astuto e sagaz, fazia trejeitos para enganar as pessoas. Tinha a expressão de uma pessoa humilde, rezava em tom sereno, com o intuito de angariar a piedade das pessoas, de ganhar esmolas. Com este amo, Lázaro aprendeu diversas orações e para diversas finalidades, principalmente para curar enfermidades das mulheres que acreditavam em suas mentiras.

Relevamos a representação da fé, utilizada pelo cego, para enganar as pessoas. Em momentos anteriores ao século XVI, esse comportamento era inadmissível, pois enganar as pessoas por meio da oração, mesmo que não fosse explicitamente, significava que pessoa estaria fora do reino dos céus, já que estaria enganando o próprio Criador. Porém, as necessidades básicas vividas pelo cego não o deixavam se intimidar com o fato de estar em "pecado". Os sentimentos e as necessidades sociais misturavam-se fazendo com que a razão se sobrepusesse à fé.

Os homens entendiam que a vida já não era mais como eles pensavam anteriormente, que eles tinham seus papéis na sociedade porque Deus queria que assim o fosse. Eles percebiam que os homens é que direcionavam suas próprias vidas, de forma que deles é que dependiam as conquistas terrenas. Com base nas tantas artimanhas do cego, Lázaro aprendeu a se defender dele. Contra a avareza do amo, que não o alimentava 
adequadamente, ele aprendeu a enganá-lo para saciar sua sede e matar sua fome, ou seja, o burlador passou a ser burlado. Com tal mestre, Lázaro aprendeu a mentir e a burlar, usando suas artimanhas para ganhar dinheiro para sua sobrevivência.

O segundo mestre de Lázaro foi o clérigo, que conseguiu ser mais avarento do que o cego, oferecendo-lhe apenas cebolas para que matasse a fome "Mira, mozo los sacerdotes han de ser muy templados en su comer y beber, y por eso yo no me desmando como otros". (ANÔNIMO, 1975, p. 116). Assim, Lázaro utilizou-se dos ensinamentos do cego para sobreviver: roubou o pão da sacristia, foi pego pelo clérigo e mandado embora. Neste tratado, Lázaro mostra sua decepção ao saber que os homens da igreja, considerados dignos de solidariedade na ajuda aos necessitados, eram egoístas e pensavam somente em si. Lázaro enfrentou a avareza e o desprezo de um membro da Igreja, estendendo sua visão negativa a todos os representantes dela. (ANÔNIMO, 1975).

O autor da obra, ao apresentar a realidade da igreja, desnudando claramente o comportamento daqueles que, até então, eram detentores do saber e dos ensinamentos a ser ministrados aos homens, mostra que os mesmos nada mais eram do que homens que representavam as mudanças sociais. O egoísmo presente nas relações sociais também se manifestava na igreja, sendo compartilhado entre os representantes de Deus na Terra.

Esse tratado, a nosso ver, contém um ensinamento de vida para o homem do século XVI: a confiança nos representantes de Deus na sociedade já não existia como outrora. O homem, nesse momento, era o "dono" das suas ações, não era culpa do Criador que ele estivesse em situação precária, sem conseguir suprir as necessidades básicas de sobrevivência. A culpa dessa situação estava sendo atribuída a sentimentos que se fortaleceram em meio às alterações econômicas, políticas, religiosas e educacionais. Estavam sendo despertados alguns comportamentos que antes estavam adormecidos, em razão da acomodação por parte daqueles que tinham sido destinados aos ensinamentos divinos perpassados pela igreja.

Em um diálogo da peça teatral denominada "Galileo Galilei", do século XX, escrita por Bertold Brecht, temos a representação da decepção do pequeno monge quando descobre que o mundo tinha mudado, que aquilo que era considerado verdade já não podia mais ser seguido, que a pobreza não era advinda de Deus e que seus pais nada mais eram do que atores de um teatro da vida, dirigido pelos homens e não pelo Ser Supremo². Por meio da fala do monge, o autor se refere ao fato de que na realidade do século XVI a vida passara por uma mudança sem volta. Sem volta porque, apesar da angústia existente na sociedade, modificada por tantas descobertas, a aceitação dessa transformação de vida teria que acontecer gradativamente. Por meio da descrição da vida dos seus pais, o monge entendia que não era possível acreditar na desconstrução de um mundo criado em muitos séculos. Era difícil despertar em um mundo totalmente diferente daquele que se acreditava existir pela vontade divina, ou seja, despertar sabendo que Deus não estava mais no centro do universo, no comando da vida dos homens.

As mudanças não aconteceram de um momento para o outro, desenvolveram-se durante séculos e, na fala do monge, fica claro que não era possível viver na "nova sociedade" sem participar de suas prioridades. As descobertas, as negociações aconteciam e, em cada experiência empírica, revelava-se um mundo totalmente diferente daquele que

2 El Pequeño Monje. (BRECHT, 1956, p. 61-62). 
os homens conheciam de forma contemplativa. Nesse sentido, quando o autor de Lazarillo de Tormes apresenta o terceiro mestre, um escudeiro, entendemos que este ensinou a Lázaro coisas essenciais para a sua sobrevivência naquela sociedade. Dentre elas, a honra e a importância de manter as aparências, já que, apesar de suas precárias condições, o escudeiro mantinha a pose de um homem bem sucedido. Para Lázaro, essa conduta não tinha nenhum valor, porque o que Ihe importava era ter comida para sobreviver. Mesmo assim, guardou tais ensinamentos.

A honra e a aparência correspondiam à tentativa de manter os costumes e comportamentos dos homens da nobreza já em decadência, pois os burgueses que, até então, eram os que serviam a seus senhores, passaram a ser proprietários da riqueza comercial. Como almejavam poder social, buscavam se portar imitando o modelo de comportamento dos nobres, embora o ensino de que precisavam não era o mesmo dedicado à nobreza. Para sua ascensão econômica, o que importava eram conhecimentos práticos, vividos no cotidiano, por meio dos quais eles adquiriam o conhecimento do mundo empiricamente.

O conhecimento teórico, dedicado outrora à nobreza, que deveria pensar, analisar a sociedade e governá-la, não se inseria nos propósitos da burguesia. O tempo, para ela, passou a ser prioridade. Não se podia "perder tempo" para pensar e analisar, era preciso agir, conhecer e desvendar os mistérios da natureza. O autor relaciona a "velha e a nova" sociedades de forma intrínseca, mostrando um emaranhado de sentimentos confusos e ao mesmo tempo reveladores para a história. Ou seja, a obra transmite ao leitor as alterações educacionais necessárias aos homens para pensar e agir de maneira diferente do modelo que já estava impregnado na sociedade. As relações humanas sempre sofrem embates quando há um confronto para possíveis alterações sociais que envolvem mudanças do que está vigente.

Como exemplo das diferentes relações que passam a existir entre os homens, quando há a necessidade de mudanças, citamos o quarto mestre de Lázaro, um frade. Sua ação é relatada em um tratado extremamente curto, porém, bem significativo para a época. Esse mestre iniciou Lázaro na vida sexual, bem como the deu os primeiros sapatos, ensinando-Ihe também os prazeres que a vida podia proporcionar. Um frade, pessoa religiosa, que perante a sociedade deveria ser um exemplo de honestidade, pureza, conforto espiritual, é que proporciona a Lázaro um ensinamento a respeito do prazer do corpo. A obra revela, portanto que aqueles princípios que caracterizavam os homens religiosos tornaram-se coisas do passado. O momento de Lázaro explicitava sentimentos e comportamentos que até então ainda se mantinham ocultos em todos os setores sociais. No entanto, para suprir as exigências do dia-a-dia, tais sentimentos e comportamentos acabaram se disseminando na sociedade.

O quinto mestre foi o buleiro, que também ensinou Lázaro a enganar as pessoas. Pela primeira vez na obra, ele se apresenta como um mero espectador das atitudes desse novo mestre e critica suas ações, a exemplo do seu posicionamento contrário à venda da bula. Entendemos que esse tratado é um símbolo do que Lázaro não podia fazer, nele ficam claras tanto a indignação do personagem quanto a crítica social que faz a pretexto do episódio. Lázaro aprende o que não se deve fazer, ou seja, que não se deve aproveitar de pessoas inocentes e pobres que, assim como ele, lutavam para sobreviver. (ANÔNIMO, 1975). 
O quinto tratado, talvez, seja aquele em que Lázaro se sente mais oprimido pelas enganações do mestre. Neste tratado, ele revela que ainda tem sentimentos de fé. Sugere que o buleiro não deveria agir de tal forma com os homens que acreditavam nos ensinamentos divinos e em sua possibilidade de curar as pessoas. $O$ mestre, segundo Lázaro, enganava com veemência os que necessitavam de um amparo para a vida espiritual, já que, com a vida que estavam acostumados a levar, aos poucos, ficaram incrédulos. Ou seja, os próprios homens da igreja agiam como os demais. Lázaro afirma que seu amo era tão convincente que conseguia enganar a todos e, mesmo aqueles que tentavam desmascará-lo, levantando dúvidas sobre a falsidade e a verdade dos seus discursos, acabavam por vezes caindo em suas artimanhas.

O buleiro utilizava o ambiente da Igreja para criar situações de convencimento. Orando com os olhos fechados e as mãos unidas, fazia longos sermões sobre a importância da bula para a cura e para uma vida melhor naquela sociedade. Quando percebia que nem todos sabiam o latim, ele discursava horas em latim, mas, segundo Lázaro, não era possível saber se realmente o latim era correto, porque, quando ele estava com pessoas que tinham o conhecimento dessa língua, discursava usando poucas palavras em latim.

No sexto tratado nominado "Cómo Lázaro se asentó con un capellán y lo que con él pasó"; começa com Lázaro descrevendo a si mesmo, "Siendo ya en este tiempo buen mozuelo, entrando un día en la iglesia mayor, un capellán della me recebío por suyo [...]" (ANÔNIMO, 1975, p. 170), Lázaro tem como mestre um charlatão, que, pela primeira vez, não é seu criado e sim seu funcionário. Lázaro inseriu-se no comércio e ganhou algum dinheiro, que, juntado por quatro anos, serviu para que ele comprasse roupas usadas. Aqui Lázaro se lembra dos ensinamentos do escudeiro, especialmente do que este lhe falou a respeito da questão da aparência, um fator importante para quem, apresentando-se como um homem de bem, queria ter sucesso na vida. O sexto mestre ensinou-lhe a arte da venda, ensinou-o a ser um bom vendedor. (ANÔNIMO, 1975).

Logo, facilitou sua inserção no mundo do comércio. Importante considerar que, nesse momento de várias mudanças, cada um dos cinco primeiros mestres lhe ensinou uma forma de sobrevivência. Desse modo, ao encontrar o sexto, ele já tinha adquirido um conhecimento prático para superar as diferentes dificuldades surgidas no dia-a-dia. De acordo com o que vai sendo apresentado em cada tratado, todos tiveram importância e significância na vida de Lázaro, mostrando que os ensinamentos correspondiam ao modo de acreditar e de agir de cada um dos mestres.

Alguns conservavam o modo tradicional de educação, porém, viam-se sem perspectivas e não conseguiam pensar em algo mais concreto do que o estômago. Outros analisavam a vida e as alterações que estavam acontecendo na sociedade com mais clareza, entendendo que o homem estava por si e que sua sobrevivência dependia de sua esperteza e de sua malandragem. Os demais revelavam sua vida e suas atitudes como sempre foram, embora antes tenham conseguido esconder, ou seja, agiam como sempre fizeram. Porém, como a sociedade vivia um momento de desconfiança e de tentativas de sobrevivência, a necessidade de serem acreditados fazia com que burlassem as pessoas em sua crença.

O último mestre foi um oficial de justiça, com o qual Lázaro viveu momentos de aflição. Assustado com tal profissão, ele abandonou o amo, começou a trabalhar como pregoeiro e passou a seguir os conselhos do arcipreste. (ANÔNIMO, 1975). No sétimo 
tratado o arcipreste de Sant Salvador, casa Lázaro com Mercedes, sua amiga. Lázaro presta-se a esse casamento por conveniência, visto que o conveniente atendia aos dois: para Lázaro, era a segurança de comida e abrigo, para o arcipreste, a manutenção de uma amiga perto de si, ou segundo as pessoas que falavam sobre o casamento, de uma amante. A conveniência, nesses termos, mostra que, na realidade do século $\mathrm{XVI}$, os homens precisavam se amparar para sobreviver. Independentemente dos sentimentos de orgulho, vergonha, traição, honestidade e fidelidade, o que importava era suprir as necessidades básicas e se inserir na sociedade.

Dessa forma, as duas obras, cada uma à sua maneira, desnudam os acontecimentos de seu período. Em Cárcel de Amor, vemos a marcante presença do amor, da preservação de sentimentos que não condizem com a sociedade fora do âmbito da nobreza. $O$ autor revela, por meio dos personagens, a luta pela manutenção da educação dos sentimentos praticados entre os nobres, isto é, aqueles que lhes foram ensinados para que se mantivessem no poder da organização social.

Lazarillo de Tormes é o contraponto de Cárcel de Amor, pois mostra o homem em sua realidade crua, sem os sentimentos nobres de lealdade e honestidade. $O$ personagem de Lázaro revela a educação de acordo como que se vive, ou seja, as mudanças de comportamentos e de ações vão ao encontro do que o faz sobreviver. O uso da razão prevalece sobre o da fé. Se, antes, o homem aguardava a sorte advinda de Deus, Lázaro desmente essa teoria, ensinando que Deus não ia dar aos homens comida, roupas, abrigo se eles não lutassem para consegui-los. Dependia de cada um lutar pelos seus ideais. As duas obras, a nosso ver, revelam claramente a transição gradual que ocorreu naqueles séculos. Do século $\mathrm{XV}$ ao $\mathrm{XVI}$, a sociedade moderna apresenta suas raízes profundas, conquistadas por longo período, e já não consegue esconder ou disfarçar suas bases de re/organização.

Os personagens de uma e outra obra, explicitamente, dividem espaço com modelos sociais diferentes. Em Cárcel de Amor, o romantismo do apaixonado e a opção pela morte para suprir sua dor mostram o sentimento do cavaleiro medieval (representado em vários romances de cavalaria como exemplo social), que luta pelos seus mais puros sentimentos. Idolatra a donzela, é educado, gentil, forte, guerreiro e respeita o seu Senhor como aquele que representa Deus. Em Lazarillo de Tormes, o cavaleiro é um homem comum, que não acredita no amor eterno e puro. Os sentimentos que prevalecem são os relacionados à preocupação consigo, com o seu bem estar, ou melhor, sua sobrevivência: o amor não saciaria sua fome. A honestidade não se apresenta como o caminho da sobrevivência, pois, muitas vezes, por meio da desonestidade é que se podia manter vivo. Desse modo, entender as obras e analisá-las como ensinamentos para os nossos dias, como afirma Marc Bloch, corresponde a compreender que a história revela os homens no seu tempo, embora estes continuem sempre sendo homens.

Com isso, entendemos que as modificações nas relações sociais de cada momento histórico configuram-se em novas condutas relacionadas ao modo como os homens produzem e se reproduzem em sociedade no atendimento de suas necessidades. Dessa maneira, eles respondem ao funcionamento e à organização da sociedade. Conforme Figueira (1998, p. 13), nesse direcionamento, é transmitido aos homens "[...] aquilo que é mais apropriado para se aprender e para se ensinar". Atualmente, o uso da razão se configura de forma mais intensificada nas relações sociais econômicas, políticas, culturais 
e educacionais. Atualmente, intensifica-se também a presença marcante da ambição, da inveja, da traição, da trapaça em prol da riqueza e do poder, ou seja, do capital. Vale destacar que tal encaminhamento é uma consequência dos acontecimentos ocorridos na história, ou seja, no passado, demonstrando que a historicidade permeia as ações do homem de hoje.

O fato é que os acontecimentos históricos se delineiam na conduta adotada pelos homens na atualidade, ou seja, a postura adotada pelo homem no presente é uma consequência do passado que não deve ser ignorada no processo de formação do homem. Consideramos, nesse contexto, que as obras clássicas abordadas ao longo do estudo são um recurso pedagógico que tende a propiciar uma compreensão da atual conjuntura dos acontecimentos presentes na sociedade, favorecendo o desenvolvimento do processo de ensino-aprendizagem. É oportuno ressaltar que esse direcionamento não se restringe a essas duas obras, mas a todas as obras clássicas. Na interpretação de Gasparin,

\begin{abstract}
Há que buscar um equilíbrio entre indivíduo e sociedade, a partir de uma visão totalizadora, sem autonomização de elementos, não privilegiando o individualismo, ou o sociologismo, ou, por outra parte, acentuando ora o subjetivismo, ora o objetivismo. [...]. Nesta perspectiva, um clássico em educação é um sinal, um testemunho de um ambiente intelectual, cultural, político e econômico que se expressa através de sua vida, vida que nos fala e aproxima de outras vidas. (GASPARIN, 2011, p. 44).
\end{abstract}

Com base nessa reflexão, enfatizamos que o homem, como um ser social, tem que ter acesso aos conhecimentos históricos que fomentam o desenvolvimento de suas ações e o funcionamento da sociedade. Para tanto, sua formação não pode ser amparada apenas em questões microssociais atuais. Assim, não é possível entendermos o homem atual sem relacioná-lo com sua historicidade, já que sua formação está ligada aos acontecimentos do passado.

Procuramos estabelecer uma conexão entre o passado e o presente, entendendo que cada período retrata o que pode retratar, sem julgar o certo, o errado ou de como deveria ser a organização da sociedade. A questão a ser analisada não vai pelo caminho do julgamento e sim pelo da leitura dos próprios autores tendo como finalidade entendermos a própria vida e a nossa forma de organização social, pois somos responsáveis por nossas ações e comportamentos. Logo, podemos dizer que os ensinamentos apresentados nessas obras se propagaram ao longo dos anos, refletindo-se em nossos dias.

\title{
Obras clássicas: conhecimento histórico para o ensino
}

Ao analisarmos a intervenção do contexto histórico espanhol dos séculos XV e XVI nas obras clássicas da literatura espanhola, Cárcel de Amor e Lazarillo de Tormes, observamos que alguns fatos ocorridos naquele momento foram alvo das críticas contidas nessas obras. Dessa maneira, entendemos que as obras clássicas são marcadas pelas relações estabelecidas entre os homens em um determinado período histórico.

Com os ensinamentos representados nas obras estudadas, podemos compreender a educação e a formação dos homens na sociedade espanhola nos momentos em que elas foram escritas. Os homens, de acordo com suas necessidades, procuraram encontrar caminhos para a sobrevivência, essas questões estão presentes nas obras clássicas 
literárias Cárcel de Amor, e Lazarillo de Tormes, nas quais estão representadas as angústias e os conflitos vividos pela sociedade dos séculos $\mathrm{XV}$ e XVI, respectivamente.

Os autores clássicos, normalmente de forma implícita, utilizam suas obras para denunciar comportamentos e situações que não condizem mais com o posicionamento socioeconômico, político, cultural e educacional da sua época. Portanto, na maioria das vezes, os autores apresentam novos ensinamentos aos homens do seu período, esclarecendo que a mudança está posta, a sociedade não é mais a mesma e que, por isso, uma nova maneira de pensar e de agir pode favorecer a organização da sociedade.

Com base nessas análises, indagamos: qual é a contribuição das obras clássicas para a formação humana? Entendemos que a leitura e o estudo das obras clássicas são, sem dúvida, indispensáveis para que façamos a articulação entre o seu presente e o passado, por meio da forma como os autores trataram as questões que surgiram em seu tempo. Segundo Bloch (1967), a compreensão do passado nos esclarece a respeito presente, já que o passado e o presente estão conectados pela formação humana. É com essa compreensão que defendermos a importância da leitura das obras clássicas. Os professores, por serem os transmissores do conhecimento científico, tendo, portanto, como responsabilidade a formação humana, devem entender que o passado faz parte da nossa realidade, ou seja, compreender que só é possível explicar as relações do presente quando se compreende que, no passado, os homens sofreram alterações sociais e precisaram de novos conhecimentos para supri-las.

De nosso ponto de vista, se os professores, principais formadores de opiniões e do senso crítico, não conseguirem relacionar os fatos presentes com as questões históricas, é improvável que os alunos adquiram uma argumentação suficiente para analisar e entender sua relação e sua posição na sociedade conflitante em que vivemos. Segundo Figueira (1998, p. 01), "[...] o papel da educação consiste em mostrar ao homem aquilo que é certo. [...] o homem precisa ser ensinado a ser homem".

Almejamos que, por meio do contato com obras clássicas, os professores consigam realizar uma reflexão aprofundada sobre o desenvolvimento do ensino ao longo do tempo. A inserção do ensino de obras clássicas nos cursos de licenciatura é uma oportunidade para que tanto para os professores formadores quanto para os futuros professores conheçam as alterações educacionais ocorridas nos diferentes períodos históricos e, assim, se fundamentem para enfrentar as questões práticas e teóricas da sala de aula. É oportuno ressaltar que a importância da leitura e do estudo de obras clássicas não se restringe aos cursos de formação docente, abrange também as demais áreas do conhecimento, a exemplo do Ensino, da Educação, da História, da Política.

Leonel (1998) afirma que, com a recorrência ao estudo dos clássicos, pode-se evitar um estudo fragmentado das questões do momento e analisar as alterações da sociedade de maneira mais ampla. O conhecimento que eles nos oferecem auxilia-nos a articular os acontecimentos do passado com os do presente, o que amplia nosso entendimento das raízes dos problemas.

A formação docente na atualidade é fragmentada e flexível às demandas da sociedade. Segundo Gasparin,

[...] parece que os professores perderam suas funções de transmissores e construtores de conhecimentos. As profundas mudanças que se estão processando na sociedade dão a impressão de que eles são dispensáveis e podem ser 
substituídos por computadores e outros equipamentos tecnológicos, por meio dos quais o educando adquire conhecimento. (GASPARIN, 2005, p. 01).

A desvalorização desse profissional não é mera coincidência e sim uma decorrência das modificações ocorridas na sociedade, fomentadas pelo processo de industrialização e urbanização no país (SAVIANI, 2011). Melo e Falleiros (2005, p. 175) lembram-nos de que o papel desempenhado pelo professor atualmente é resultado da reforma do Estado brasileiro a partir dos anos 1990. Nesse momento, ocorreram "[...] significativas alterações na relação entre Estado e sociedade civil [...]", a exemplo da promulgação de políticas a favor do mercado ${ }^{3}$.

Por meio de aparelhos ideológicos, as ações promovidas pelo Estado tendem a estabelecer um consenso espontâneo nas classes dominadas. "Dentre os aparelhos, aquele que possui vetor dirigido à formação dos sujeitos por meio das orientações emanadas do Estado tem sido a instituição escolar" (PLATT, 2009, p. 37). Portanto, é possível entender que as políticas aprovadas pelo Estado para orientar a formação de professores funcionam como um instrumento ideológico. Saviani analisa esse processo:

Ao longo dos últimos dois séculos, as sucessivas mudanças introduzidas no processo de formação docente no Brasil revelam um quadro de descontinuidade, embora sem rupturas. A questão pedagógica, de início ausente, vai penetrando lentamente até ocupar posição central nos ensaios de reformas da década de 1930. Mas não encontrou, até hoje, um encaminhamento satisfatório. Ao fim e ao cabo, o que se revela permanente é a precariedade das políticas formativas, cujas sucessivas mudanças não lograram estabelecer um padrão minimamente consistente de preparação docente para fazer face aos problemas enfrentados pela educação escolar em nosso país. (SAVIANI, 2011, p. 10).

Com base nesse autor, podemos pontuar que, no Brasil, as mudanças ocorridas na formação inicial dos professores não tiveram resultados significativos. O descaso com a formação continua sendo alarmante e, ao mesmo tempo, desesperador, pois a falta de preparação do docente para enfrentar os problemas educacionais repercute-se na educação básica. Nas interpretações de Saviani (2011) e Gasparin (2011), o trabalho do professor acaba sendo orientado pelo vício de se atender às exigências do mercado de trabalho, ou seja, é marcado pela,

[...] urgência em dar respostas. Estas, com freqüência, por serem imediatistas, pouco se preocupam com a reflexão, com a fundamentação teórica, com a análise. O que importa é o autor que está na moda, o último livro que foi lançado sobre o assunto, nem sempre tendo na devida conta o que traz de novo. (GASPARIN, 2011, p. 37).

De nossa perspectiva, a não utilização de obras clássicas no processo do ensino e

\footnotetext{
3 "A partir de uma suposta constatação de que a crise enfrentada pelo capitalismo mundial decorria da natureza burocrática e excessivamente regulatória do Estado, a classe dominante e dirigente brasileira, no início da década de 1990, instituiu mecanismos para minimizar tanto o raio de ação do Estado em sentido estrito na vida em sociedade como seu papel na condução dessa sociedade. Nesse primeiro momento, tal cruzada contra o Estado esteve acompanhada pela apologia do mercado como instância central para organizar a vida coletiva, empreendendo-se uma árdua defesa pela privatização de empresas públicas e a implantação de políticas públicas sociais sob a justificativa de que o mercado, como mecanismo de regulação, seria muito mais eficaz do que o Estado, obtendo melhores resultados com menores custos". (MELO; FALLEIROS, 2005, p. 175).
} 
da aprendizagem está relacionada às ações educacionais do Estado, que, por sua vez, atende à demanda momentânea. Argumentamos que tal conduta tem deixado falhas na formação de professores, já que têm sido priorizados os acontecimentos do presente, sem a preocupação com o entendimento do passado. As pesquisas atuais são, na maioria das vezes, estudos sobre fatos que aparentam ser novidade na sociedade, mas que, na verdade, são consequência de mudanças históricas, de alterações que ocorrem em momentos de transição.

Desse modo, compreendemos que não se incentivam os profissionais do ensino para um estudo mais reflexivo, o que é estranho, pois a leitura aprofundada de autores clássicos que tratam das questões sociais, políticas e educacionais promove uma compreensão mais aperfeiçoada da própria realidade, ocasionando uma formação qualitativa. De fato, a leitura e a análise dos clássicos podem ser entendidas como um instrumento para se pensar em uma formação na sua totalidade. Isso proporcionaria aos docentes condições de perceber e entender as relações do ensino e da educação com a sociedade, entender que estas áreas de atuação não são separadas dos demais acontecimentos sociais.

Leonel (1998, p. 87) aponta que "A premissa de que o passado, quando examinado do ponto de vista do conflito entre forças produtivas e relações sociais de produção, é mais esclarecedor do presente do que o presente está em condições de esclarecer". Dessa maneira, a história deixa de ser um objeto de curiosidade e passa a ser utilizada como um instrumento de reflexão a respeito dos eventos humanos. Com isso, afirmamos que ensinar requer contextualizar o conteúdo, diferenciar as questões sociais do momento estudado e estabelecer um elo entre o passado e o presente para o entendimento das questões que são trabalhadas pelo professor em sala de aula.

Neste trabalho, apresentamos as duas obras clássicas como exemplo da necessidade de se ler e entender o passado. Compreendendo os escritos desses dois autores, concluímos que os séculos XV e XVI são dois momentos de grandes alterações sociais, cujos homens passavam por conflitos e angústias que os levavam a questionar seu papel na sociedade. Muitas vezes, eles não se identificavam nem com uma sociedade nem com outra e tentavam manter as relações sociais que existiam em momentos anteriores. No entanto, já não se conseguia, no presente, manter a ordem e a educação de outros momentos.

Nesse caso, a análise das obras esclarece sua importância no ensino de hoje, já que nelas está implícita uma crítica à sociedade. Elas mostram as contradições que permeiam as instâncias sociais e que dificultam o desenvolvimento e a re/organização da sociedade. A luta pela sobrevivência é clara, as experiências comungam com as "velhas" e "novas" relações. O autor, muitas vezes, posiciona-se na própria obra como mediador e/ou como narrador da autobiografia, mostrando que, apesar de ele entender as questões de sua época, nem sempre consegue esclarecer o que ele considera como certo ou errado. Ele vive o momento e ensina que as atitudes humanas se emaranham de forma conflituosa e, assim, transmite ensinamentos a respeito de valores essenciais para a organização e o desenvolvimento dos homens na sociedade, o que torna a obra clássica.

Leonel (1998, p. 88) assinala que, "[...], uma obra antes de resistir ao tempo e tornar-se clássica é uma obra histórica e continua sendo depois desse reconhecimento". Portanto, podemos dizer que uma obra clássica descreve a história da época, situa-a em 
seu devido tempo e espaço. Consequentemente, ao mesmo tempo em que nos incentiva a atribuir importância aos acontecimentos do período, ela nos induz a refletir sobre o que somos e o que podemos ensinar no momento em que vivemos.

Oliveira e Mendes asseveram que,

Em uma determinada época, nos diferentes campos do conhecimento e da arte, surgem autores que se destacam dentre os seus contemporâneos e permanecem como uma referencia para as gerações seguintes. É verdade que algumas vezes o reconhecimento não ocorre na vida do autor. Mas, a partir de dado momento tornam-se aquilo que denomina 'um clássico'. (OLIVEIRA; MENDES, 2010, p. 08).

Conforme a análise realizada por Oliveira e Mendes (2010), entendemos que autores clássicos, em diferentes áreas do conhecimento, escrevem obras que representam o período em que foram escritas e atravessam gerações sem perder seu valor. As obras clássicas ensinam-nos a refletir sobre as questões humanas, ou seja, sobre a necessidade de definir regras e planejar o ensino de uma maneira que contemple a formação do homem para a vida em sociedade. Nesse sentido, consideramos relevante definir o que é um clássico, na visão de alguns autores.

Segundo Saviani e Duarte,

[...], clássico é aquilo que resistiu ao tempo, tendo uma validade que extrapola o momento em que foi formulado. Define-se, pois, pelas noções de permanência e referência. Uma vez que, mesmo nascendo em determinadas conjunturas históricas, capta questões nucleares que dizem respeito à própria identidade do homem como um ser que se desenvolve historicamente, o clássico permanece como referência para as gerações seguintes que se empenham em aprimorar-se das objetivações humanas produzidas ao longo do tempo. (SAVIANI; DUARTE, 2012, p. 31).

Já Calvino (2007) pondera que,

O clássico não necessariamente nos ensina algo que não sabíamos; às vezes descobrimos nele algo que sempre soubéramos (ou acreditávamos saber), mas desconhecíamos que ele o dissera primeiro (ou que de algum modo se liga a ele de maneira particular). E mesmo esta é uma surpresa que dá muita satisfação, como sempre dá a descoberta de uma origem, de uma relação, de uma pertinência. (CALVINO, 2007, p. 12).

Calvino (2007, p. 12) ainda assinala que "Um clássico é uma obra que provoca incessantemente uma nuvem de discursos críticos sobre si, mas continuamente a repele pra longe". De tais definições, retiramos a ideia de que uma obra clássica é sempre atual, mesmo abordando acontecimentos ocasionados em séculos anteriores, justamente por transmitir pontos reflexivos sobre a vida em sociedade. Nesse sentido, Calvino (2007, p. 16) afirma que "[...] os clássicos servem para entender quem somos e aonde chegamos".

$\mathrm{Na}$ interpretação de Gasparin (1997, p. 40), um clássico é "[...] autor ou obra que, por sua originalidade, pureza de estilo e, acima de tudo, pelo fundo e forma irrepreensíveis, constitui um modelo digno de imitação". Aprendemos com esse autor que um clássico ultrapassa seu tempo, por marcar a época em que foi escrito. Segundo Oliveira e Mendes,

[...] os autores que se tornaram clássicos são aqueles que souberam captar questões da sua época e as responderam com mais profundidade de que seus 
contemporâneos. [...], um autor não se torna clássico somente por essas qualidades, ou seja, por ter captado com profundidade as exigências de sua época. Ele se torna um clássico também por se converter em uma referência para as gerações seguintes. Nesse sentido sua obra extrapola o seu tempo e os homens das épocas vindouras encontram nela um estímulo e sugestões para refletirem sobre as questões que the foram colocadas. (OLIVEIRA; MENDES, 2010, p. 09).

Destarte, existem várias definições para o termo clássico. Apesar dessa variedade, em termos gerais, todas revelam o mesmo caminho, ou seja, que uma obra clássica é uma fonte inesgotável de conhecimentos, além de ser uma descoberta e uma redescoberta de saberes. No Brasil, a leitura da obra clássica ainda não é muito valorizada na discussão, mesmo nos cursos de licenciaturas. Frequentemente somos indagados por perguntas e afirmações a exemplo das seguintes. Qual a contribuição e/ou a importância do estudo de autores de períodos tão anteriores ao nosso? Devemos nos preocupar com as questões presentes. A dúvida sobre a importância desses estudos e a dificuldade de se relacionar passado com o presente, muitas vezes, levam-nos a entender o conhecimento superficial que, muitas vezes, é trabalhado nas escolas da educação básica e, também, no ensino superior.

Se analisarmos os estudos realizados na Europa, como em Portugal, por exemplo, vemos que a valorização dos autores clássicos é considerada imprescindível para o conhecimento do aluno; inclusive, a maioria das universidades tem cursos específicos de Estudos Clássicos, cujos objetivos ficam claros na própria página de apresentação. Dentre eles:

Antes de mais, Estudos Clássicos servem para quem quer Saber. Ao encontrar-se na origem de grande parte dos fenômenos culturais do mundo contemporâneo, seja por imitação seja pela rejeição dos modelos herdados da Antiguidade, os Estudos Clássicos permitem adquirir um entendimento mais profundo da cultura ocidental. Estamos, por isso, convictos de que estudar Estudos Clássicos não implica de modo nenhum um estreitamento das perspectivas, como se apenas nos interessassem as 'coisas velhas' e bafientas: é nossa convicção que não se pode estudar a Cultura, a Filosofia ou a Literatura Medieval, mesmo quando escritas já em Português, Inglês ou Italiano sem um sólido conhecimento de Latim; também não compreendemos como pode alguém estudar a sério Camões ou Shakespeare, Petrarca ou Rabelais, Milton, Garrett, Pessoa ou Elliot sem conhecer os Clássicos; tal como não é possível estudar o pensamento político contemporâneo sem os modelos gregos e romanos; ou mesmo muito do que são o teatro e cinema contemporâneos sem os modelos antigos. Estudos Clássicos servem também para aprender a Pensar. Era costume antigamente dizer-se que o Latim e o Grego eram a Matemática das Letras. Em grande medida, esta comparação é justa, uma vez que estas línguas exigem considerável destreza mental. Estudos Clássicos servem ainda para os alunos ganharem Experiência e Maturidade Intelectual que Ihes permitam enveredar por praticamente qualquer curso de Mestrado na área das Humanidades e Ciências Sociais. (DEC, 2015, p. 01).

Os objetivos do Departamento de Estudos Clássicos da Universidade de Lisboa (DCE) esclarecem a importância desse estudo. Segundo eles, o aluno, quando faz a pesquisa de autores considerados clássicos, amplia seu conhecimento, conseguindo realizar uma reflexão crítica sobre sua realidade e também favorecendo sua formação humana e profissional. Por tudo isso, consideramos que a leitura de obras clássicas é indispensável para que o professor faça a articulação entre o contexto do presente e os desígnios históricos construídos nas relações estabelecidas pelos homens na vida em sociedade nos diferentes períodos. Reiteramos, portanto, que isso nos auxilia a entender e 
a compreender as demandas históricas que fundamentam as representações sociais, as ideias e a educação ao longo dos anos.

Leonel (1998) argumenta que, por esse caminho, podemos esclarecer melhor o presente; as teorias clássicas auxiliam os docentes a compreender seu trabalho cotidiano. Gasparin (2011, p. 38) afirma que, no trabalho pedagógico-educacional, o professor deve utilizar os clássicos, porque estes, ao

[...] captar as questões vitais de uma determinada fase do desenvolvimento da humanidade, tornaram-se modelos para todos os que procuram ler o tempo atual. Desta maneira, tem sentido retornar aos clássicos a fim de avançar, de progredir. (ibidem).

Existem vários autores que escrevem a respeito da utilização de obras clássicas na formação de docentes. No entanto, não se observa muito interesse em utilizá-los no processo de formação docente. A nosso ver, seria necessário que, nos cursos de licenciatura, para o desenvolvimento do processo de ensino e aprendizagem, o profissional/docente, contemplasse a utilização desses autores para a sua formação, haja vista que sua importância não fica restrita ao conhecimento apropriado pelos professores, mas a uma grande demanda de alunos, ou seja, influenciando direta e indiretamente o ensino.

\section{Considerações finais}

Ao longo deste estudo, procuramos oferecer uma amostra da riqueza incalculável de detalhes contidos nas obras clássicas de diferentes períodos, mostrando o que cada informação pode nos revelar das exigência de formação do homem nos momentos de transição. Para tanto, escolhemos Cárcel de Amor, do século XV, e Lazarillo de Tormes, do século XVI, Na análise dessas obras, pudemos detectar, de forma perculilar, os discursos de cunho crítico e reflexivo, relacionados ao contexto histórico em que foram escritas. Além das mesmas revelam-nos que o ensino pode ser estabelecido com base nas relações humanas interdisciplinares, sejam elas educacionais; econômicas; políticas; religiosas, visando a formação completa dos homens na sociedade.

Vale destacar que, em Cárcel de Amor, temos a expressão das relações de sentimento (amor) e poder na nobreza, na corte dos Reis Católicos. Já, em Lazarillo de Tormes, estão descritos alguns fragmentos da sociedade espanhola naquele momento histórico, como a luta pela sobrevivência, a decadência do cavaleiro medieval e a conduta de alguns membros da Igreja Católica. Consideramos que os autores das duas obras literárias espanholas revelam muitas vezes temas sombrios de seu momento histórico.

Nesse caso, o contexto social não é visto por um viés héroico, mas realista: apresentam-se as dificuldades enfrentadas pelas classes sociais de suas épocas. Os autores, muitas vezes, procuram demonstrar, por meio dos personagens, a necessidade de relacionamento humano para o ensino. Esclarecem que a sociedade, em momentos de transição, não consegue revelar de forma clara seus anseios e suas angústias, mas, ao mesmo tempo, explicitam os sentimentos e os comportamentos que se alteram de acordo com as relações que os homens estabelecem para atender às prioridades que lhes estão sendo apresentadas.

É importante ressaltar que, no momento histórico em que essas obras foram 
escritas, as perseguições e censuras aos escritos eram constantes. A denúncia ou crítica, de forma clara ou não, a algum segmento e hierarquia social acarretaria, muitas vezes, a perseguição, o julgamento e até mesmo a condenação do escritor da obra. De qualquer forma, tudo isso expressa a historicidade.

Não podemos deixar de reiterar que a leitura dos clássicos, de modo geral, é um desafio: inclui pensar, refletir e destacar que o entendimento do passado favorece a compreensão do presente. Reafirmamos que não estamos comparando passado e presente, mas, sim, destacando a necessidade de que todos entendam as questões que perpassam os diferentes momentos históricos. Cada realidade social envolve sempre a formação humana, revelando que a formação dos homens sempre foi e continua sendo uma preocupação do ensino seja no passado seja no presente.

Conforme já nos posicionamos, o trabalho com as obras clássicas deveria estar presente no ensino. Compreendemos que, para o aluno, falta interesse por essas leituras porque elas exigem conhecimento histórico, concentração, disciplina, reflexão e interpretação. Tais questões, consideradas essenciais para a formação do aluno, na maioria das vezes, não são tratadas como tais pela escola e/ou pelo professor.

Em geral, considera-se que o aluno, para se interessar pelo conteúdo da disciplina, precisa entender as coisas mais práticas, relacionadas à sua realidade imediata. Entretanto, o ensino e o conhecimento pela via prática, sem a teoria, torna-se superficial, de forma que o aluno retorna e/ou permanece no senso comum. Isso dificulta a formação da qual a sociedade precisa, embora não dê condições para que sua necessidade seja atendida: um profissional qualificado. Dessa forma, relacionando a falta de interesse por estudos mais aprofundados cientificamente, seja por falta de incentivo seja pelo distanciamento temporal desses estudos em face das transformações tecnológicas, seja pela falta de preparo de conhecimento e de incentivo do professor para esses estudos, o que temos é um sistema educacional defasado.

Contudo, tendo em vista a importância histórica para a compreensão das questões presentes na atualidade, afirmamos que, por meio do estudo e da reflexão sobre as obras clássicas, podemos (re)significar nossas ações e comportamentos e, como resultado, o conhecimento. Logo, ao entender que o passado é a continuidade das relações humanas que perpassaram séculos até se consolidarem nas sociedades posteriores, os professoresformadores e futuros professores poderão atualizar suas teorias e práticas e, assim, refletir acerca de questões do ensino na sociedade em que estão vivendo.

Em conclusão, destacamos que a leitura de obras, como Cárcel de Amor e La vida de Lazarillo de Tormes y de sus fortunas y adversidades, favorece a descoberta do caráter histórico da educação, do ensino e das relações presentes na sociedade, caráter esse impresso na escrita dessas obras. Elas coadunam os limites individuais e coletivos de um determinado período histórico, revelam valores que orientam o ensino e consequentemente a formação humana, bem como proporcionam um melhor entendimento da nossa realidade.

\section{Referências}

ANÔNIMO. La vida de Lazarillo de Tormes y de sus fortunas y adversidades. Edición Alberto Blecua. Madri, Espanha: Clásicos Castalia, 1975.

$\mathrm{BLOCH}$, Marc. Apologia da história ou oficio de historiador. Rio de Janeiro: Jorge 
Zahar, 1949.

(Coleção saber).

CALVINO, Ítalo. Por que ler os clássicos. São Paulo: Companhia das Letras, 2007. CASANOVA, José Francisco Ruiz. Introdução. In: SAN PEDRO, Diego de. Cárcel de amor: tractado de amores de Arnalte y Lucenda. Semón. Espanha, Madri: Anaya, 2008. p. 09-52.

DEC, DEPARTAMENTO DE ESTUDOS CLÁSSICOS. Porquê estudos clásicos? 2015. Disponível em: <http://www.tmp.letras.ulisboa.pt/dec/\#pqclassicas-acesso>. Acesso em: 04 mai 2015.

FIGUEIRA, Pedro de Alcântara. A educação de um ponto de vista histórico. Revista Intermédio, Campo Grande, MS, v. 1, n. 1, p. 11-15, 1998.

GASPARIN, João Luiz. Comenio: A emergência da modernidade na educação.

Petrópolis, RJ: Vozes, 1997.

2011.

Comenio: a emergência da modernidade na educação. Petrópolis, RJ: Vozes,

Uma didática para a pedagogia histórico-crítica. 3 ed. Campinas, SP: Autores Associados, 2005 (Coleção educação contemporânea).

LEONEL, Zélia. Para ler os clássicos: lições de Montaigne. Revista Intermeio, Campo Grande, MS, v. 04, n. 08, p. 6-16, 1998.

MELO, Marcelo Paula de; FALLEIROS, lalê. Reforma da aparelhagem estatal: novas estratégias de legitimação social. In: NEVES, Lúcia Maria Wanderley (Org.). A nova pedagogia da hegemonia: estratégias do capital para educar o consenso. São Paulo: Xamã, 2005. p. 175-192.

OLIVEIRA, Terezinha; MENDES, Claudinei Magno Magre. Reflexões sobre os clássicos na história. In: OLIVEIRA, Terezinha (Org.). História e historiografia da educação nos clássicos: estudos sobre antiguidade e medievo. Dourados: UEMS, 2010.

PLATT, Adreana Dulcina. O currículo da formação humana: uma resposta ao pragmatismo moderno. In: gestão. Curitiba: CRV, 2009. p. 29-43.

SAN PEDRO, Diego de. Cárcere de amor. Tradução de C. Giordano. São Paulo: Imprensa Oficial de São Paulo; Oficina do Livro Rubens Borba de Moraes, 2010.

SAVIANI, Dermeval. Formação de professores no Brasil: Dilemas e perspectivas. Revista Pedagógica, v. 09, n. 01, jan./jun. 2011. Disponível em:

$<$ www.revistas.ufg.br/index.php/poiesis/article/view/15667/9592>. Acesso em: 10 jan. 2015.

SAVIANI, Dermeval; DUARTE, Newton. Pedagogia histórico-crítica e luta de classes na educação escolar. Campinas, SP: Autores Associados, 2012. 
CONCEIÇÃO SOLANGE BUTION PERIN é professora da Universidade Estadual do Paraná/ Unespar - campus de Paranavaí e Doutora em Educação pela Universidade Estadual de Maringá - UEM.

Endereço: Rua Santa Joaquina de Vedruna, 1792 - 87015-150 - Maringá/PR - Brasil. E-mail: solperin01@gmail.com

SILVANA MALAVASI é professora da Universidade Estadual do Paraná/Unespar - campus de Apucarana e Mestre em Ensino pela Universidade Estadual do Paraná - Unespar. Endereço: Av. Minas Gerais, 5021 - 86800-970 - Apucarana/PR - Brasil.

E-mail: silvanamalavasi@hotmail.com

Recebido em 21 de abril de 2016.

Aceito em 18 de julho de 2017. 